\title{
Appraisal of the Fischer-DiPasquale-Wheaton (FDW) Real Estate Model and Development of an Integrated Property and Asset Market Model
}

\section{H du Toit and C E Cloete}

Department of Construction Economics, University of Pretoria

\begin{abstract}
This paper provides a concise overview of the development of an integrated property and asset market model (IPAMM) for South African property markets, utilising the Pretoria office market as case study. The IPAMM simulates the interrelationships between property and asset markets in a diagrammatic quadrant model configuration. The Fischer-DiPasquale-Wheaton (FDW) real estate model, arguably the most advanced diagrammatic quadrant real estate model available at present, served as basis for the development of IPAMM. IPAMM is essentially a regression model based on a system of stochastic equations that captures the interrelationships between property and asset markets. The model advances beyond mere conceptualisation of these relationships to a quantified interpretation and application of the theoretical premises that represent the micro-foundations of economic behaviour in property and asset markets.
\end{abstract}

JEL L85, R21, 31

\section{INTRODUCTION}

Viezer (1999: 503) aptly states that, “(i)n the past, academics and investment managers have had difficulty in linking information from the markets for leasable space and asset ownership claims. The former is often referred to as the 'space market' and the latter as the 'capital market.' For almost fifteen years, academics have attempted to analytically integrate these two markets”.

Integration of these markets has been accomplished in the Fischer-DiPasqualeWheaton (FDW) real estate model, which is arguably the most advanced diagrammatic quadrant real estate model available at present. This model served as basis for the development of an integrated property and asset market model (IPAMM) for South African property markets, utilising the Pretoria 
office market as case study. The value of such a model is that it provides a powerful conceptual instrument that integrates a spectrum of endogenous and exogenous economic and property market variables into a comprehensible framework, illustrating the potential effect of numerous market fluctuations on general equilibrium. Coupled to the comprehensible schemata of stochastic equations incorporated in the model, an innovative heuristic device is rendered.

\section{BACKGROUND TO THE FDW MODEL}

Hendershott \& Ling (1984) co-authored the first article that attempted to integrate real estate space and capital markets. This model evaluated investment value responses to tax code alterations in a dynamic programming algorithm that used a traditional discounted cash flow equation with assumed parameters. In 1987, Corcoran graphically illustrated the two interdependent markets and distinguished between short- and long-run supply of space. The next set of refinements comprised an "... elegant diagrammatic exposition in three similar articles: Fisher (1992), DiPasquale and Wheaton (1992) and Fisher, Hudson-Wilson and Wurtzebach (1993)” (Viezer, 1999: 504).

The most recent formally published development is a quantitative version of the DiPasquale-Wheaton model (1992) that was published on the Curtin Business School website in 1999 with an accompanying description of the model, coauthored by Fischer, DiPasquale and Wheaton (2001) - hence the term FDW Model. The FDW model, which utilised the Perth office market as case study, conceptualises the interrelationships between the following four markets:

- $\quad$ Market for space

- Asset valuation

- Construction sector

- $\quad$ Stock adjustment.

\section{RECONSTRUCTION OF THE FDW MODEL}

\section{Defining the model}

The FDW Model is a static, quadrant model that traces the relationships between real estate market and asset market variables, as well as the adjustments that take place to establish equilibrium in the supply of and demand for real estate (Figure 1). 
The model is founded on the principles of demand and supply modeling: therefore, the demand for own real estate assets must equal its supply (DiPasquale \& Wheaton, 1996: 6). Hence, the primary objective of the model is to determine market equilibrium: i.e. the amount of floor space demanded and offered at a given price level or rent.

\section{Figure 1 The Quadrant FDW Model}

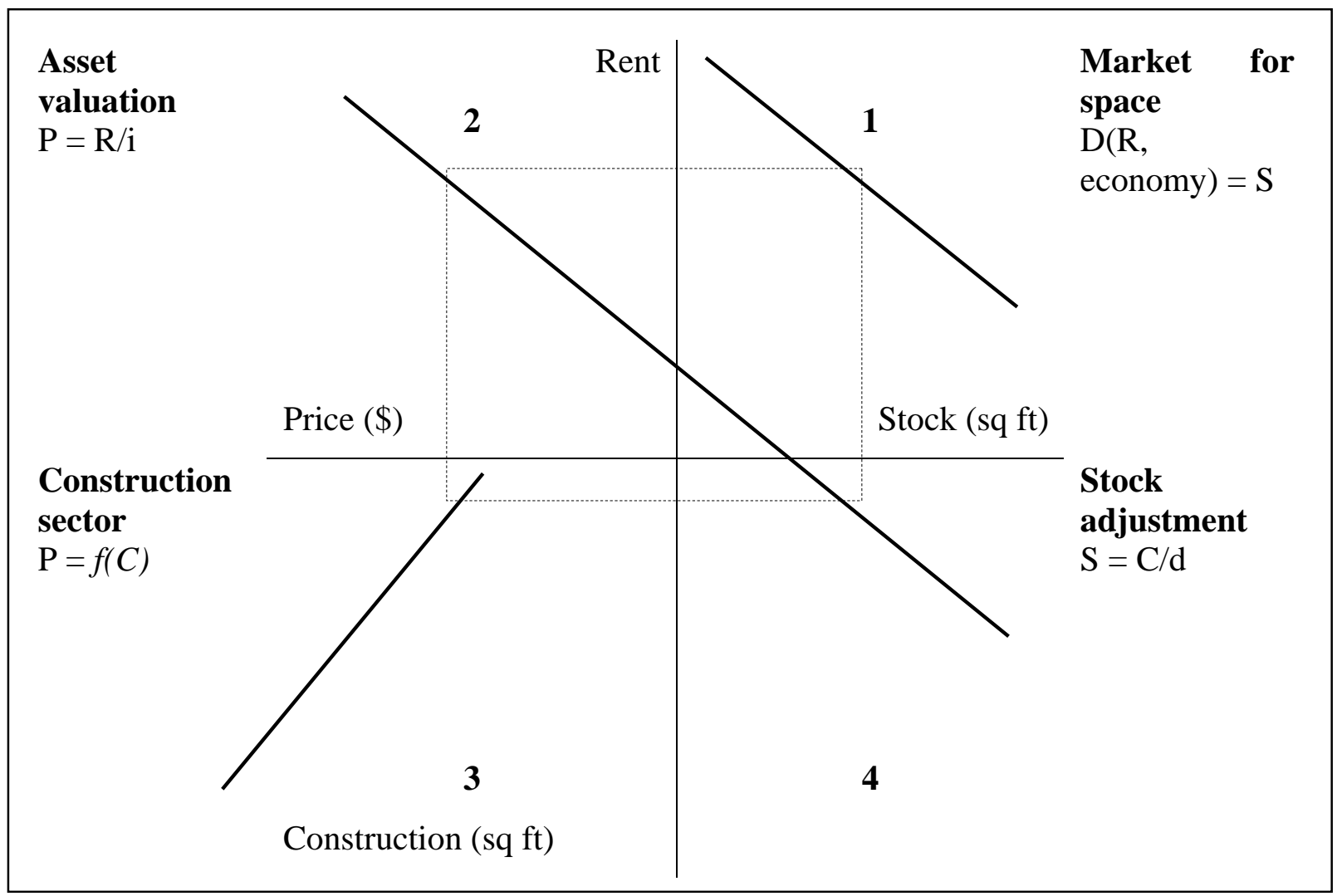

Source: DiPasquale \& Wheaton, 1996

In equilibrium, the supply of real estate space should be equal to demand at a specific price level (Quadrant 1). The price paid for real estate assets by an investor is a function of real or imputed rent (Achour-Fischer, 1999: 34). Rent is translated into property values when, in the capital market, rentals are capitalised at an appropriate capitalisation rate (Quadrant 2). The difference between property values and replacement cost per unit triggers the supply of new development (Quadrant 3). Even in strictly static conditions, a certain level of construction is required to maintain stock at the required equilibrium: a portion of stock is always subject to demolition, withdrawal or deterioration (Quadrant 4). Adjusted stock, i.e. new construction less losses, is converted into a long-run stock of real estate space (back to Quadrant 1). 


\section{Reconstruction of the FDW model}

The particular website on which the model was originally published, and more specifically the FDW Excel Model, could not be accessed. This meant that the FDW model had to be reconstructed. In addition, complete data sets are not shown in the literature. This problem is complicated by the fact that formulae quoted in the literature are shown in processed format. Hence, figures and parameters could not be derived directly from these formulae. Furthermore, literature sources are, in some instances, inconsistent and confusing (see e.g. Achour-Fischer, 1999: 40).

The data problem was subsequently addressed by gleaning information from a combination of sources, including the textbook and relevant articles. Data applicable to Quadrant 1 was obtained from Achour-Fischer (1999: 40-41). In Quadrant 2, an assumption had to be made concerning the market capitalisation rate. The second data limitation was encountered in Quadrant 3, where an assumption had to be made concerning the minimum rate required to initiate new construction. The depreciation rate (Quadrant 4) that had been applied to determine the total long term stock supply was obtained from DiPasquale and Wheaton (1996: 10).

In most instances, the output from one quadrant provided input to the next. Due to the fact that a relatively complete data set was available for Quadrant 1, the model could be reconstructed quadrant for quadrant. In so doing, workable data sets were generated.

\section{Model results}

Table 1 summarises and compares the results obtained by means of the reconstructed FDW Model and data on the Perth (Australia) office market, quoted in published literature. Comparison with the Perth office market was chosen because a complete set of results was available (Achour-Fischer, 1999: 40-41).

The Perth office market is in equilibrium at a rental rate of $\$ 201.78 / \mathrm{m}^{2} / \mathrm{annum}$. At this rate, there is a total demand for 1.64 million square meters of office floor space. Based on reconstructed data, market equilibrium was modeled at a rental rate of $\$ 199.69 / \mathrm{m}^{2} /$ annum, which translates into a total demand for 1.65 million square meters of office floor space.

Model results that were obtained by means of the above mentioned exercise revealed a statistical variance of 0.6 per cent from the findings of the original Perth office market example. Based on these results, the pro forma spreadsheets 
were deemed to be sufficiently accurate to apply as basis for the development of an Integrated Property and Asset Market Model (IPAMM) for the City of Pretoria.

Table 1 Comparison of reconstruction results and data quoted in published literature

\begin{tabular}{|l|c|c|c|}
\hline Variable & $\begin{array}{c}\text { Literature } \\
\text { FDW }^{\mathbf{1}}\end{array}$ & $\begin{array}{c}\text { Reconstructed } \\
\text { FDW }^{\mathbf{2}}\end{array}$ & $\begin{array}{c}\text { Variance } \\
\mathbf{( \% )}\end{array}$ \\
\hline Total long run stock $\left(\mathrm{m}^{2}\right)$ & 1644444 & 1650295 & 0.35 \\
\hline Annual rent per unit $\left(\$ / \mathrm{m}^{2}\right)$ & 201.78 & 199.69 & 1.05 \\
\hline Price of construction $\left(\$ / \mathrm{m}^{2}\right)$ & Not shown & 1815.32 & $\mathrm{n} / \mathrm{a}$ \\
\hline Annual new construction $\left(\mathrm{m}^{2}\right)$ & 16444 & 16503 & 0.35 \\
\hline Average & - & - & 0.6 \\
\hline
\end{tabular}

Source: 1 Achour-Fischer (1999: 40-41)

2 Reconstructed FDW Model, April 2002

\section{Nature of applications}

It is important to note that the FDW Model is designed for comparative static analysis. Tracing the effects of single variate or multi-variate manipulations through the various quadrants of the model can simulate market conditions. The model does not account for time lags that invariably occur in the process of re-adjusting to market equilibrium. These dynamic aspects fall outside the ambit of the FDW Model.

\section{Concluding remarks on the FDW model}

1. The model provides a framework that illustrates the relationship between real estate use and real estate assets. This framework illustrates, inter alia, the inverse relationship between short-term real interest rates and property values.

2. Single variate shifts seldom occur and it is more likely the case that economic events cause several shifts to occur simultaneously. For example, if the economy contracts, employment creation slows down and short term interest rates tend to rise. It is, therefore, more likely that multivariate shifts will occur in the model. Although this results in a more complex analysis, the net result is still a combination of the impacts of each individual shift.

3. The model presents a framework that illustrates the effect of exogenous changes on new equilibria. However, the model does not give an accurate account of the intermediate stages of market adjustment. Hence, time lags that commonly occur are not accounted for. 


\section{DEVELOPMENT OF AN INTEGRATED PROPERTY AND ASSET MARKET MODEL FOR SOUTH AFRICAN MARKETS}

The next phase of the research initiative applied the reconstructed FDW Model framework to develop an Integrated Property and Asset Market Model for the City of Pretoria. For the purposes of this analysis, the Pretoria office market was selected as case study. The study focuses on formal office space, including all grades of office floor space in the CBD and decentralised locations. The study excludes office space in the form of dwelling house offices, as well as office space ancillary and subservient to retail and industrial land uses.

Historic office market data was utilised for a specific time period (1997). The use of historic data facilitated comparison between model results and factual data, i.e. results of a modeling exercise could be compared to actual market conditions that were known to have prevailed at that particular point in time. Hence, availability of secondary data facilitated model calibration.

\section{General assumptions and economic fundamentals}

In addition to the general assumption of perfect competition in the economy, diagrammatic quadrant models such as the FDW model and IPAMM are generally based on the following assumptions that are more specific to the real estate environment:

1 The capitalisation technique provides a basic and acceptable mechanism to model the inverse relationship between interest rates and property values.

2 There is a definitive minimum rate, expressed as construction cost per unit (e.g. $\mathrm{R} / \mathrm{m}^{2}$ ) that will trigger new development.

3 Even in strictly static conditions, a certain minimum level of construction is required to maintain equilibrium in the supply of space. This can be ascribed to the fact that a portion of stock is always subject to demolition, withdrawal or deterioration. The model assumes that these losses can be measured and expressed in terms of a depreciation rate, which is a constant percentage of the existing stock in a static model (AchourFischer, 1999: 37).

4 The model assumes a straight-line simplification of the relationship between relevant variables in each quadrant.

5 In effect, the model is insensitive to the nature and structure of the construction industry and its local idiosyncrasies.

6 It is assumed that there is a determinable ratio of labour to floor space utilisation rate in each real estate market. For example, in the offices sector, the average office worker occupies $20 \mathrm{~m}^{2}$. Independent studies, for 
example Hakfoort \& Lie (1996: 183-96), have verified that there is a distinct utilisation rate for each real estate market (e.g. offices and retail) and, furthermore, that these ratios differ for each geographic market area.

7 The model assumes that development is mainly private sector driven. The effects of land grants and other types of government incentives that impact on real estate markets are not factored into the model. It may, however, be argued that such grants and incentives influence local economic activity in a certain geographic area and that the indirect effects thereof are factored into the model via Quadrant 1.

8 Due to the interactive way in which the quadrants are linked, the model may create the impression that there are no time lags involved in the process of re-adjusting to equilibrium.

9 As far as the relevance and applicability of the model is concerned in a market dominated by owner-occupied real estate, it is assumed that the decisions of owner-occupiers and tenants are influenced by the same economic and capital market conditions; that these owner-occupiers have the same investment motives as tenants; and that the model therefore behaves identical in both types of markets (DiPasquale \& Wheaton, 1996: 10-11).

\section{Specific IPAMM assumptions and delimitations}

The aim of the IPAMM model development process was to test the model and subsequent results in terms of available data and not, per se, to test the validity of secondary data itself. In the context of the above, specific model assumptions were limited to the following:

1 The model incorporates an equilibrium vacancy rate of five percent (5.0 per cent).

2 The stock depreciation rate is assumed to be one percent (1.0 per cent) per annum.

3 For reconstruction purposes, the slope of the demand curve is assumed to be 0.5 . A slope of 0.5 implies that market demand and supply conditions are perfectly elastic.

$4 \quad$ Market impacts are distributed evenly throughout the geographic office market landscape, i.e. the model does not differentiate between impacts on the CBD versus decentralised office locations.

5 Associated with point four above, market data with specific reference to rentals, property values, construction rates, vacancy rates, the capitalisation rate and depreciation rate, reflect market averages across a spectrum of office locations and grades. As such, the model does not distinguish between micro market differences. 
6 The model therefore, in effect, assumes a similar risk and return profile for all office locations and grades.

7 The static model portrays the 1997 Pretoria office market in an equilibrium state, i.e. all internal and external forces have been fully accounted for in the model.

\section{Data specifications and modeling}

Table 2 summarises key source data variables utilised in the Pretoria IPAMM modeling exercise. A comparison of subsequent modeling results and actual market data is shown in Table 3.

Table 2 Pretoria IPAMM key source data variables

\begin{tabular}{|l|c|}
\hline Variable & Key source data variables \\
\hline Number of office workers ${ }^{1}$ & 79000 \\
\hline Annual stock depreciation rate $(\%)^{2}$ & 1.00 \\
\hline Space per office worker $\left(\mathrm{m}^{2}\right)^{3}$ & 20.00 \\
\hline Market capitalisation rate $(\%)^{4}$ & 13.44 \\
\hline Minimum construction price $\left(\mathrm{R} / \mathrm{m}^{2}\right)^{5}$ & 2150 \\
\hline
\end{tabular}

Source: 1 Urban-Econ (1998)

2 Assumption, derived from FDW Model

3 Urban-Econ (1998)

4 Rode \& Associates (1997)

5 Rode \& Associates (1998)

Key source data variables substituted in the Pretoria IPAMM include an office market labour force of 79000 workers; a space utilisation rate of $20 \mathrm{~m}^{2}$ per office worker; a market capitalisation rate of 13.44 per cent; and a minimum construction price of $\mathrm{R} 2150 / \mathrm{m}^{2}$. The annual stock depreciation rate was assumed to be 1.0 per cent per annum.

Main findings of the modeling exercise that were generated by substituting these variables in the Pretoria IPAMM are shown in Table 3. Prevailing market conditions (1997) include a total long run stock of $1599600 \mathrm{~m}^{2}$ at a weighted average rental rate of R30.04/ $\mathrm{m}^{2}$, with a standard deviation of R3.46 (calculated from Rode, 1998). These market conditions compare favourably to Pretoria IPAMM results of $1599248 \mathrm{~m}^{2}$ at an average rental rate of R30.69/m².

The Pretoria IPAMM model's predicted rental differs 2.16 per cent from the weighted average of the market data and is well within a standard deviation of the market data. The long run stock prediction is within 0,02 per cent of the actual data. Taking cognisance of the macro level at which the Pretoria IPAMM 
simulation occurs, the variance between model results and prevailing market data is deemed to be negligible.

Table 3 Comparison of market data and Pretoria IPAMM results

\begin{tabular}{|l|c|c|c|}
\hline \multicolumn{1}{|c|}{ Variable } & Market data & $\begin{array}{c}\text { Pretoria } \\
\text { IPAMM }\end{array}$ & $\begin{array}{c}\text { Difference } \\
\text { (\%) }\end{array}$ \\
\hline Rent per unit $\left(\mathrm{R} / \mathrm{m}^{2}\right)$ & 30.04 & 30.69 & 2.16 \\
\hline $\begin{array}{l}\text { Annual new construction } \\
\left(\mathrm{m}^{2}\right)\end{array}$ & 22491 & 15993 & Not relevant \\
\hline Total long run stock $\left(\mathrm{m}^{2}\right)$ & 1599600 & 1599248 & 0.02 \\
\hline Average & - & - & 1.2 \\
\hline
\end{tabular}

Concerning the estimated level of annual new construction, it should be noted that the estimated level of annual new construction $\left(15993 \mathrm{~m}^{2}\right)$ in terms of the Pretoria IPAMM will not necessarily equate to actual new construction that occurred in the office market during $1997\left(22491 \mathrm{~m}^{2}\right)$. This can be ascribed to a number of factors including, inter alia, the following:

- The Pretoria IPAMM, as is the case with the FDW Model, assumes a straight-line simplification of the construction function. In practice, the construction sector reveals cyclical tendencies.

- The Pretoria IPAMM simulates an equilibrium level of annual new construction that is required to satisfy equilibrium demand. The equilibrium vacancy rate of 5.0 per cent does not reflect construction induced vacancy. Furthermore, the construction sector is typified by phases of overbuilding as a consequence of, inter alia, speculative development. Subsequent phases are characterised by reduced levels of building activity during which the take-up rate of available space increases. Actual construction levels are therefore influenced by a number of factors to which the model is insensitive, including construction levels that are artificially inflated or deflated by subjective, end-user decision-making processes; and excess, construction-induced stock capacity in the market.

- The FDW Model, and hence the Pretoria IPAMM, is not sensitive to the nature and structure of the construction industry and its local idiosyncrasies. The model does therefore not necessarily reflect the uniqueness of localised micro market conditions.

In the context of the above, it follows that a direct comparison of estimated annual new construction and actual construction in the market should acknowledge the nature and structure of the construction industry. 


\section{Introducing impacts to IPAMM and scenario modeling}

The objective of this section is to illustrate the combined effect of impacts that typically occur in, respectively, property and asset markets. These impacts occur as the result of a complex sequence of processes, linkages and decisions in the market. Roulac (1996: 323-46) provides a strategic real estate framework that aims to identify and describe these processes, linkages and decisions. The property and asset markets reflect a series of strategic interactions between users and suppliers of space, resulting in real estate transactions (Roulac, 1996). Roulac argues that the "... confluence of the initiatives and decisions of those who utilise space with those who are involved in creating and controlling it are filtered through a series of transaction interaction forces, including:

- $\quad$ Property market conditions

- $\quad$ Space user strategies, resources and priorities

- $\quad$ Competing investment performance

- $\quad$ Service provider and developer/deal-maker initiatives

- Capital market conditions

- $\quad$ Economic activity

- Business consumer confidence

- $\quad$ Public sector policies, priorities and programmes” (1996: 337, 45).

The net effect of these interacting forces can be traced to financial input-output relationships in the property and asset market. It is these aspects that the FDW model aims to illustrate. The above-mentioned study by Roulac identifies important factors that affect property and asset market equilibrium. Fisher (1992: 161-80) developed a framework that identifies and categorises a number of macro factors that influence this equilibrium state. The framework within which these macro changes occur, and its relation to user and capital market equilibrium is illustrated in Diagram 1. In this diagram, Fisher (1992: 163-6) identifies spatial and non-spatial macroeconomic impacts that influence the supply of and demand for real estate space and real estate assets.

Diagram 1 illustrates that these impacts on the model are influenced by, inter alia, aspects such as international oil prices, the level of industrial production, defense spending, export earnings, inflation, exchange rates, interest rates and tax law changes. 


\section{Diagram 1 Factors affecting space and capital market equilibrium}

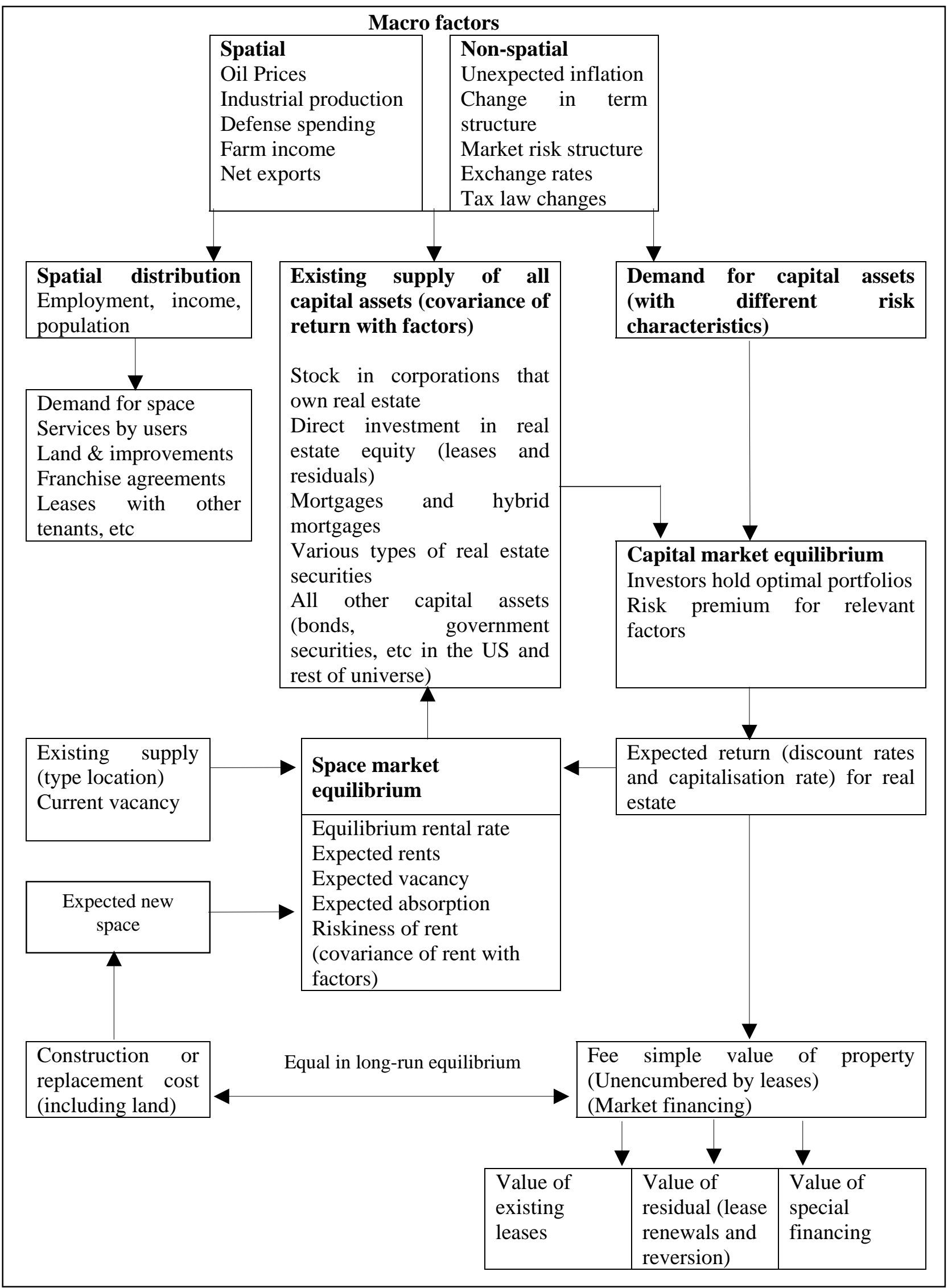

Source: Fisher (1992: 164) 
In addition to these macro aspects, the model is also influenced by local market real estate dynamics, including current rents, expected rents, vacancy, absorption rate, risk, return and investors’ portfolios (Fisher, 1992: 164).

According to DiPasquale and Wheaton (1992: 190-197 and 1996: 10-8), these aspects culminate in three broad impacts on the FDW Model, as illustrated above.

- $\quad$ Economic growth and the demand for real estate use

- $\quad$ Long term interest rates and the demand for real estate assets

- $\quad$ Short term credit availability, construction costs and the supply of new space.

Fluctuations in these variables can result in either a proportionate shift, a disproportionate shift or a unilateral shift in a specific quadrant of the model (cf. also AIREA, 1987: 34-39). Each impact has different repercussions on the model. In each case, the quadrant that is initially affected should be identified. These impacts can then be traced through each of the other three quadrants. This comparison of different long-run solutions, also referred to as market equilibrium, in a model in called comparative static analysis (DiPasquale \& Wheaton, 1996: 11). The impact of these external impacts on the model is subsequently discussed.

\section{Economic growth and the demand for real estate use}

Economic growth, in terms of the FDW Model, translates into increased production, employment, household income or the number of households (DiPasquale \& Wheaton, 1992: 190-193 and 1996: 11-13). Depending on which of these variables define the parameters for the demand curve (Quadrant 1 ), the curve will respond by means of a unilateral movement outwards. The term unilateral indicates that only the demand curve will shift. Initially, only Quadrant 1 is affected.

An economic expansion of this nature will have the effect that more space is demanded at current rents. Supply is relatively static over the short term. In terms of the laws of supply and demand, increased demand against fixed supply will therefore force rental upward. Higher rentals translate into greater asset prices (Quadrant 2) that, in turn, encourages new construction (Quadrant 3). Over time, new construction increases available stock (Quadrant 4) and the market tends toward a new equilibrium state. 
The shift in equilibrium brought about by an economic expansion need not necessarily be a proportional shift: the nature of the shift that occurs is a function of the elasticity and hence, slopes of the various curves.

An economic expansion therefore increases all equilibrium variables in real estate markets. In general, a recession is characterised by higher vacancy and lower levels of construction, whilst during an economic recovery, vacancy is lower and construction activity increases (DiPasquale \& Wheaton, 1996: 13). Caution should be taken not to generalise this statement. Independent research (Pyhrr et al., 1989: 485-89) indicates that a period of overbuilding in the real estate cycle, which typically follows an economic expansion, is initially accompanied by higher than normal vacancy rates. Thereafter, as take-up increases, vacancy decreases. This state is maintained into the initial phases of an economic recession, when construction activity declines and space utilisation increases. These findings therefore suggest exactly the opposite: during an economic expansion, new construction leads to higher vacancy and vice versa. It should, however, be noted that prolonged periods of economic recession, accompanied by a general decline in business growth, will eventually lead to higher vacancy.

The FDW Model does, however, not give an accurate account of these intermediate stages of market adjustment. Hence, models designed for the purpose of comparative static analysis do not describe the behaviour of variables during the transition from one equilibrium to another. This shortcoming needs to be borne in mind when interpreting and applying the FDW Model.

\section{Long term interest rates and the demand for real estate assets}

The demand for real estate assets is determined by real estate yields in relation to the after tax yield of fixed income securities and other investments. Aspects such as long term interest rates, growth in rentals, risk and taxation influence real estate yields. These aspects are reflected in the capitalisation rate. These parameters influence the slope of the curve in Quadrant 2.

If interest rates in the economy rise, the capitalisation rate rises and investors demand a higher return from real estate. Higher returns can not be realised from current rents and the yield from real estate becomes low relative to other investment options. Investors will therefore shift their funds from real estate to other investments in their portfolios. Under these conditions, the capitalisation rate rises and the curve in Quadrant 2 rotates in a clockwise direction, lowering real estate asset prices. Greater perceived risk and adverse tax changes have a 
similar effect on the curve in Quadrant 2. The converse may also occur, causing asset prices to rise.

Due to lower asset prices, construction activity contracts (Quadrant 3) and this decreases the annual supply of new construction. In the long run, less stock comes onto the market (Quadrant 4), forcing rentals upward (Quadrant 1). Higher rent levels bring the market into equilibrium.

The text book assumes that capital market efficiency adjusts the prices of particular assets and that each investment therefore earns a common, riskadjusted after-tax total rate of return (DiPasquale \& Wheaton, 1996: 14).

\section{Short term credit availability, construction costs and the supply of new space}

Short term credit availability and construction costs influence the supply schedule for new construction (Quadrant 3).

Construction costs may rise due to a number of factors. These factors include, inter alia, higher short-term interest rates, scarcity of construction financing, and stricter zoning and planning regulations. If any of these factors deteriorate, construction costs rise and profitability declines, resulting in a unilateral outward shift of the construction function (Figure 4). Therefore, the minimum value $\left(\mathrm{R} / \mathrm{m}^{2}\right)$ required to justify some level of new development increases.

At current asset prices, construction activity will decrease, the annual level of new construction will decrease (Quadrant 3); the long term supply of stock will be relatively lower (Quadrant 4); rents will rise (Quadrant 1); and asset prices will rise (Quadrant 2), thereby bringing the market to a new equilibrium state.

\section{IPAMM SCENARIO MODELING}

The preceding paragraphs predominantly focused on the simulation of an equilibrium state in property and asset markets. In practice, this equilibrium state is influenced by one or a combination of factors. Three scenarios were subsequently generated by means of the Pretoria IPAMM to illustrate the effect of typical market fluctuations on an equilibrium state:

- $\quad$ Scenario 1: Demand shift

- Scenario 2: Shift in capitalisation rate

- Scenario 3: Shift in construction costs. 
Each of these scenarios is subsequently discussed and conceptually illustrated.

\section{Pretoria IPAMM scenario 1: Demand shift}

The impact of a demand shift on the model is a function of the mathematical definition of the demand curve. An increase in demand may be ascribed to, inter alia, economic growth; natural population growth and subsequent growth in the number of qualified service sector employees; and in migration of service sector employees to an economically prosperous region. In the Pretoria IPAMM, the demand curve is defined in terms of, inter alia, the number of office workers in the Pretoria economy. A demand shift was subsequently by means of an increase in the number of office workers.

All other factors being equal, an increase in demand for office space causes the demand curve to shift in an easterly direction, from D1 to D2. The net effect of this demand shift is illustrated in Figure 2. The impact on market equilibrium can be summarised as follows:

- An increase in the number of office workers increases the demand for office space (Quadrant 1)

- $\quad$ At fixed short term stock supply levels, higher rentals can be demanded (Quadrant 1)

- Higher rentals result in an appreciation of asset values and prices (Quadrant 2)

- Higher asset values stimulate activity in the construction sector (Quadrant 3)

- New construction activity increases the long run supply of stock (Quadrant 4)

Increased long run stock restores market equilibrium.

\section{Pretoria IPAMM scenario 2: Shift in capitalisation rate}

In the second scenario, an increase in perceived investment risk in the market is factored into the Pretoria IPAMM by means of an increase in the market capitalisation rate. Higher capitalisation rates may be the consequence of higher real interest rates, or an increase in perceived investment risk in a specific area due to spatial and/or a-spatial factors.

An increase in the capitalisation rate rotates the asset valuation curve in a clockwise direction, from V1 to V2. The net effect of an increase in market risk on each of the Pretoria IPAMM quadrants is illustrated in Figure 3. 
Figure 2: Demand shift in terms of the Pretoria IPAMM

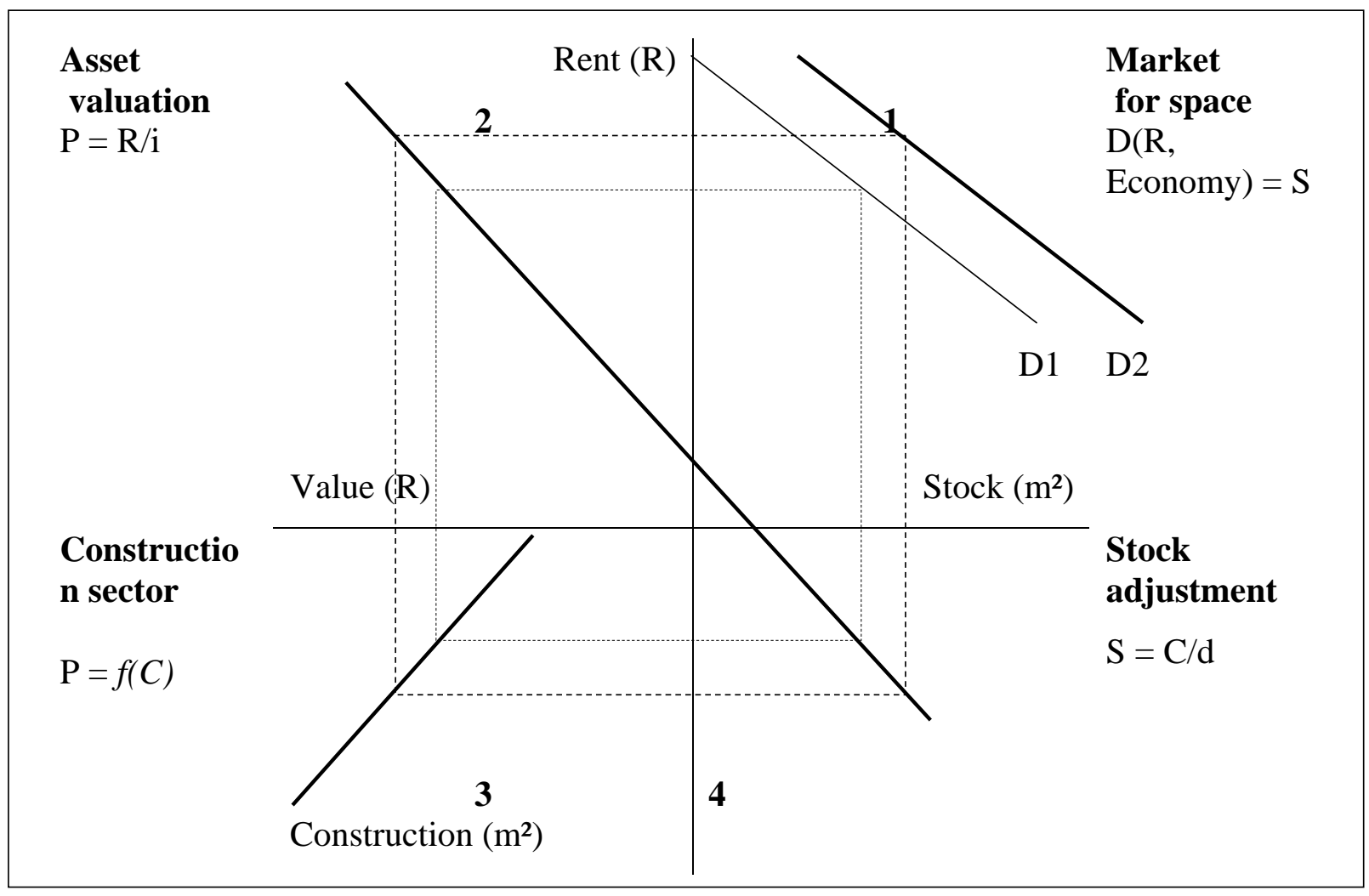

The Pretoria IPAMM illustrates the net effect of this shift in the market capitalisation rate on property and asset market equilibrium as follows:

- Higher investment risk translates into a higher market capitalisation rate (Quadrant 2)

- In the short term, asset prices depreciate as other types of investments present more secure and lucrative opportunities and subsequently siphon off potential investors from the property sector (Quadrant 2)

- $\quad$ As a consequence, construction activity decreases (Quadrant 3)

- $\quad$ Additions to total long run stock diminish (Quadrant 4)

- $\quad$ Limited supply systematically inflates rentals (Quadrant 1)

- $\quad$ Increased rentals restore market equilibrium.

\section{Pretoria IPAMM Scenario 3: Shift in construction costs}

The third scenario illustrates the effect of increased construction costs on market equilibrium. Construction costs are influenced by a number of factors, including macroeconomic variables such as interest rates, production price inflation (PPI) and import inflation; as well as by a spectrum of micro location factors such as the cost and availability of construction materials, soil type and the structure of local labour costs. 


\section{Figure 3 Shift in capitalisation rate in terms of the Pretoria IPAMM}

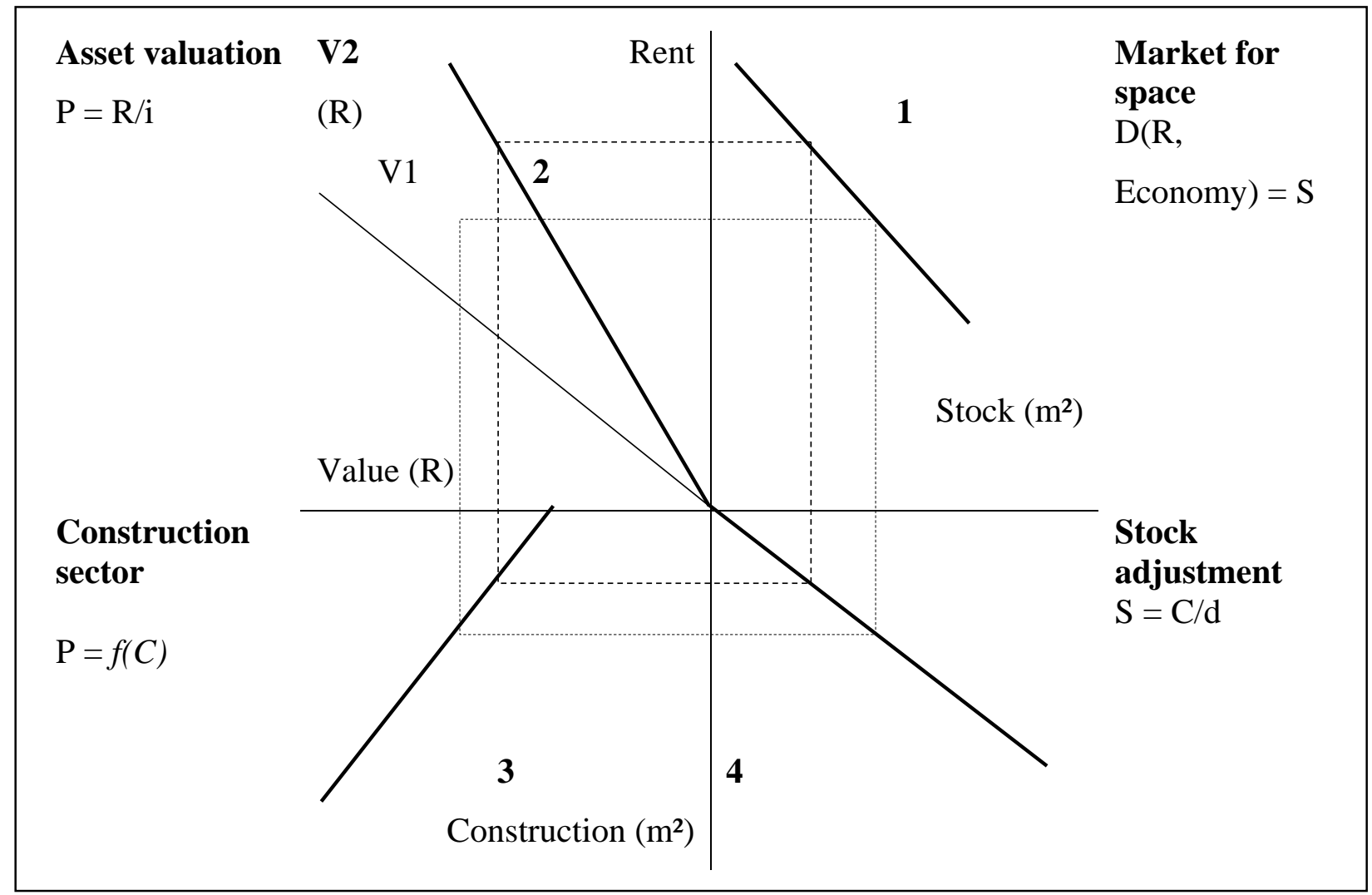

In response to an increase in construction costs, the minimum rate required to initiate new construction increases and the construction cost curve shifts in a westerly direction, from C1 to C2, as illustrated in Figure 4.

In terms of the Pretoria IPAMM, the effect of increased construction costs on market equilibrium can be summarised as follows:

- Initially, the increase in construction costs stun construction activity (Quadrant 3)

- $\quad$ Additions to total long run stock diminish (Quadrant 4)

- Due to relatively fixed supply, market rentals escalate over time (Quadrant 1)

- A combination of reduced supply and increased rentals, inflate existing asset values and prices (Quadrant 2)

- Inflated asset values justify new construction at the higher construction cost rate, thereby restoring market equilibrium 


\section{Figure 4 Shift in construction costs in terms of the Pretoria IPAMM}

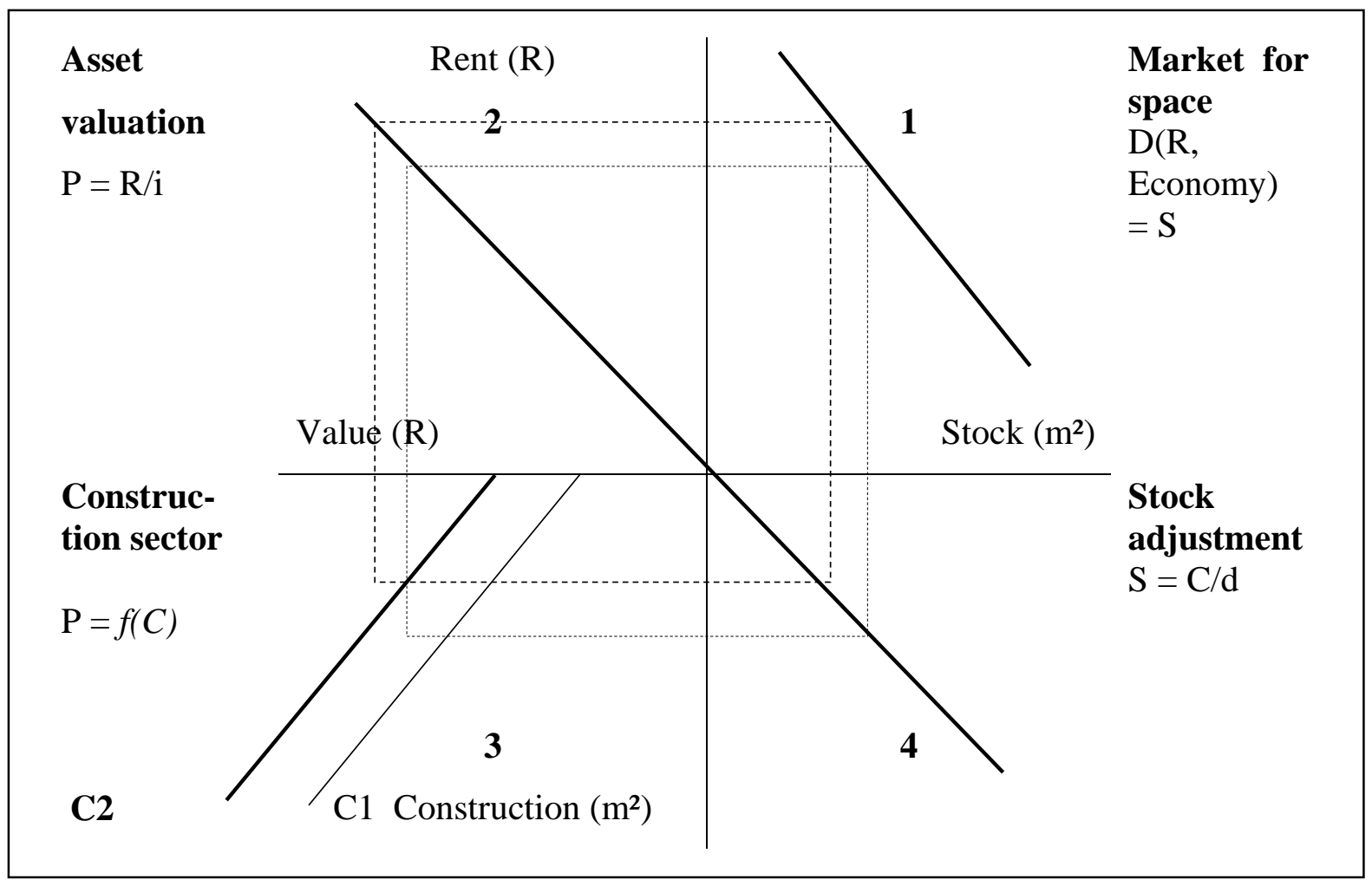

\section{Interpretation of results and validity of findings}

The Pretoria IPAMM simulation results outlined above indicate that the model successfully simulated an equilibrium state in the Pretoria office market. In the course of developing and adjusting the Pretoria IPAMM to simulate local property and asset market equilibrium, a number of factors were observed that merits comment. In this respect, interpretation of the above mentioned Pretoria IPAMM results should take due cognisance of the following:

1 The Pretoria IPAMM proved to be extremely sensitive to changes in certain key variables, in particular the minimum construction price, parameter ' $a$ ' and parameter ' $b$ '. These are calibration parameters that determine the demand curve slope in Quadrant 1. The latter parameters therefore influence demand elasticity. This level of sensitivity suggests that the model is more suitable for macro analyses, for example a citywide office market analysis, than micro analyses, for example a neighbourhood or precinct analysis.

2 Similar to the FDW Model, Pretoria IPAMM assumes perfect demand elasticity. Prevailing market conditions are not necessarily perfectly elastic. This implies that users of the model have to be particularly mindful of the assumptions on which the model is based. 
3 In practice, supply is relatively inelastic due to the fact that real estate is a fixed, non-liquid asset. Assume, for instance, that the Pretoria IPAMM is manipulated by means of an increase in the market capitalisation rate. The net result suggests that total long run stock demand (Quadrant 4) will decline from its previous level. In this particular instance, model results point to a relative decline in demand for stock, rather than an absolute decline in available stock levels.

4 Pretoria IPAMM is a static model that provides a snapshot of the market at a given point in time. As such, the model does not explicitly recognise and reflect the cyclical, and therefore dynamic nature of property and asset markets. Interpretation of Pretoria IPAMM results should not loose sight of the cyclical nature of market demand and supply.

5 Finally, in terms of the theory on which the FDW Model and hence, the Pretoria IPAMM is based, static models do not attempt to explain the behaviour of variables during the transition from one equilibrium to another. The Pretoria IPAMM therefore does not recognise time lags that invariably occur in the market adjustment process.

\section{Concluding remarks on the IPAMM}

The following can be concluded with regard to the IPAMM model development and application process:

- The Pretoria IPAMM modeling exercise indicate that the model has specific strengths and weakness that dictate its application possibilities.

- $\quad$ Due to the great number of variables that influence market equilibrium and the intricate relationships between these variables, application of the model requires in-depth knowledge of the stochastic equations and interrelationships on which the Pretoria IPAMM is based. An understanding of the internal dynamics of the model is essential to ensure judicious data modeling.

- The objective of the modeling exercise was to empirically test the relevance of the principles on which the model is based and not, per se, to evaluate the accuracy of secondary data sources. Hence, it should be noted that, prior to application of Pretoria IPAMM in practice, calibration parameters of the model need to be further refined, in particular parameters ' $a$ ' and ' $b$ ' of the construction function (Quadrant 1) that portray demand elasticity. 


\section{APPRAISAL OF THE IPAMM CONCEPT}

A critical assessment of the FDW model, and specifically the IPAMM, reveals a number of assumptions and characteristics.

\section{Recursive device}

IPAMM is a short-run, period-by-period adjustment model based on regression principles that facilitates, by means of comparative static analysis, predictions of user market supply and demand relationships in the long run. As such, the model is a recursive device, based on an iterative process. Due to these characteristics, the model tends to oversimplify dynamic market adjustment and subsequent lags that occur in the equilibration process.

\section{Stock and flow characteristics}

The model portrays stock and flow characteristics. Stock refers to existing space utilised for office (or other as defined) purposes, whereas flow relates to the provision of new space. In accordance with the scale and longevity of the stock of commercial buildings, new supply accounts only for a small proportion of total stock.

It is this uneven flow characteristic, dictated by market forces, that introduces the cyclical dimension into the market. IPAMM is ideally suited to simulate the stock scenario due to its static nature. Modeling of flow scenarios is only possible by means of an iterative process of comparative static analysis, i.e. modeling a sequence of static stock scenarios. This requires user skill and judicious decision-making on sensible assumption scenarios. The number of variables combined into the model, coupled with the intricate relationship between variables suggest that even the most skilled property practitioner will find this task challenging.

\section{Perfect market competition}

The integrated property and asset market model concept postulates perfect market competition. Perfect market competition implies that all agents involved in the property market must base their investment decisions on perfect and complete market knowledge concerning market indicators such as rentals, asset values, returns on investment, availability of space by type and location, proposed new developments that will come on stream in the short term and, importantly, the cyclical nature of the building industry. 
The cyclical nature of the building industry introduces the concept of developer and investor expectations. Such expectations can either be naïve or rational. Naïve expectations imply a line of thinking that the future would be the same as the present. Rational expectations, on the other hand, imply that developers use their knowledge of the property market, the wider economy and the best available theories of how the two function and interrelate. This dimension of the model places the responsibility squarely on the user of IPAMM to accurately express variables, such as capitalisation rates, in expectational terms. Ball, Liziere \& MacGregor support this notion (1998: 36-39).

\section{Property values, market prices and replacement costs}

The price determinant technique applied to estimate property values, uses rent as space market proxy for the capital market value of real estate assets (Quadrant 2). In this instance, IPAMM assumes that property values and market prices are synonymous, i.e. that valuations accurately reflect prevailing market prices. It should be noted that there are circumstances in which this assumption does not necessarily hold true. Apart from minor discrepancies that may occur as a consequence of interplay between macroeconomic and building cycles, market prices may vary significantly from property values in precincts where environmental decay has a detrimental effect on achievable market prices.

Applications of the model should heed the potential pitfalls associated with modeling exercises involving highly centralised spatial urban markets. Coupled with this aspect, is the occurrence of economic obsolescence and the translation of these environmental qualities into sensible modeling parameters.

In conclusion, it should be recalled that, in terms of the IPAMM, new construction will take place at the point where property values equal replacement costs (Quadrant 3). Replacement costs therefore serve as precursor to new development. In this respect, integrated property and asset market models define replacement costs comprehensively in order to include not only direct construction costs, but also other on-costs related to site clearance, financing and land costs.

\section{Separate property development industry}

IPAMM assumes that there is a separate property development industry that provides completed projects to investors. In reality, however, many developers are also investors who retain certain properties after the initial investment has occurred. In itself, this assumption does not have a direct influence on the model. The indirect effect, however, occurs when there is a marked increase in 
the occurrence of owner occupied buildings, as opposed to leasing, in the market area as a whole. In reality, this introduces complexities pertaining to market rentals versus bond installments, escalation rates and a distinction between direct vacancy, sub-lease vacancy and total vacancy. However, integrated property and asset market models assume that:

- the decisions of owner-occupiers and tenants are influenced by the same economic and capital market conditions;

- $\quad$ owner-occupiers essentially have the same investment motives as tenants; and

- $\quad$ annual rent per square meter is but one mechanism that can be utilised to express the utility value of real estate.

Owner-occupied commercial property has costs of use that implicitly constitute rent. This is often referred to as imputed rent (Ball, Liziere \& MacGregor, 1998: 19). In essence, it can therefore be concluded that integrated property and asset market models behave identical in owner-occupier and rental markets.

\section{Indirect effect of government intervention in the property market}

In terms of South African public law, government sector is not permitted to speculate in the property market or, for that matter, to engage in activities aimed at attaining financial gain. Government intervention in the property market, however, extends beyond direct intervention. Indirect government intervention in the property market includes taxation measures and special development programmes that influence spatial property markets.

The first mechanism at government's disposal is taxation. Capital Gains Tax (CGT) came into effect in South Africa on 1 April 2002. In this respect, there appears to be general consensus among property practitioners that the impact of CGT on the property market will mainly be confined to an 'add-on' to property prices, as opposed to serving as deterrent to property investment. Concerning the after tax rate of return, IPAMM assumes that capital market efficiency adjusts the prices of particular assets and that each investment therefore earns a common, risk-adjusted after-tax total rate of return. These adjustments are accounted for in Quadrant 2 of the model, the Market for Asset Valuation.

Another sphere of government influence in the property market, involves spatial development programmes. In certain geographic locations, these programmes may distort the property market in terms of, inter alia, spatial settlement patterns, property prices and rentals. These programmes may induce large scale building activity at distorted market prices due to, inter alia, incentivised development and the fact that government does not necessarily adhere to the 
free market capitalistic premises on which integrated property and asset market models are based. Application of the IPAMM in a market characterised by such extraordinary conditions may yield distorted results.

\section{Benefits of integrated property and asset market models}

As stated in the introduction, academics and investment managers have had difficulty in linking information from the markets for space and capital markets where real estate assets are valued. In other words, the distinction between use decisions and investment decisions, and the links that were conceptually known to exist between these markets, proved to be problematic in as far as its quantification was concerned.

The FDW Model that was initially conceived in 1992 provided not only a diagrammatic exposition, but also one of the first quantified mechanisms that captured the basic interrelationships between property and asset markets. As such, it advanced beyond mere conceptualisation of these relationships to a quantified interpretation and application of the theoretical premises of modernday economics that represent the micro-foundations of economic behaviour in property markets.

Diagrammatic integrated property and asset market models, such as IPAMM and FDW, illustrate the potential effect of numerous market fluctuations on general equilibrium. Although they do not explicitly account for time lags and dynamic adjustments that occur in the market equilibrium adjustment process, these models integrate a spectrum of endogenous and exogenous economic and property market variables into a comprehensible framework.

The relatively simple layout of these diagrammatic quadrant models provides a powerful conceptual instrument which, coupled with its comprehensible schemata of stochastic equations, renders it an innovative heuristic device with, inter alia, pedagogical value.

\section{Limitations of integrated property and asset market models}

General limitations of these models relate to its static nature and the subsequent inability to illustrate the dynamic process of adjustment to market equilibrium.

In addition to these general limitations, Viezer (1999: 503) advances three criticisms against diagrammatic integrated property and asset market models. First, these models assume the capitalisation rate is exogenously determined. Instead, it is contended that a multi-factor asset pricing model should be used to determine the appropriate discount rate that, in turn, would determine both the 
market value and capitalisation rate. Secondly, these models suggest that equilibrium is a natural state and that all values are determined simultaneously. However, as duly noted, in reality time lags do occur in market adjustment. Thirdly, diagrammatic models can forecast general levels and changes in direction for real estate markets, but “... it can not be used to compare one market to another. To be useful to the practitioner, the diagrammatic model needs to be statistically estimated in individual markets.” (Viezer, 1999: 503). The latter criticism offers, in itself, a relatively simple solution: to ensure optimum accuracy, the model needs to be statistically estimated for each individual market.

A concluding remark, rather than a point of criticism, relates to the use of a depreciation factor to 'capitalise' annual flow of construction into a long-run total supply of stock (Quadrant 4). Once again, the quantitative result should ideally be interpreted as a static outcome based on prevalent market conditions, rather than a mean value of cyclical time series data. This aspect, once again, relates to the static nature of integrated property and asset market models and the imminent fact that a predictive time series can only be attained by means of an iterative process in which key variables are manipulated sensibly and knowledgably.

\section{APPLICATION POSSIBILITIES}

The IPAMM Matrix of Application Possibilities identifies a number of use options and potential user markets for each application of the model. IPAMM provides useful application possibilities to each of the three core disciplines within the property sector, namely property development, property management and property valuation, as well as sectors that provide strategic services to property practitioners, namely banking and finance, and tertiary education. Table 4 summarises these application possibilities and potential user markets in matrix format.

In each of the above mentioned sectors, strategic planning and decision making actions are based on two factors, namely:

- $\quad$ historic market data; and

- $\quad$ subjective expectations on future market behaviour.

IPAMM, as analytical instrument, incorporates a broad spectrum of endogenous and exogenous variables in the most influential markets that impact on the property business, namely the market for space, asset valuation and the construction sector. As such, it provides an intelligible framework that adds 
structure to data. Hence, IPAMM is ideally suited to aid strategic decision making processes in the sectors identified in Table 4.

The list of IPAMM application possibilities and user markets is by no means exhaustive. It merely serves to illustrate the multifaceted nature of IPAMM and its subsequent relevance to a spectrum of property practitioners. An emphasis on the inclusive, integrated nature of IPAMM, rather than its limitations, should serve as catalyst for exploring creative application possibilities.

Table 4 IPAMM matrix of application possibilities

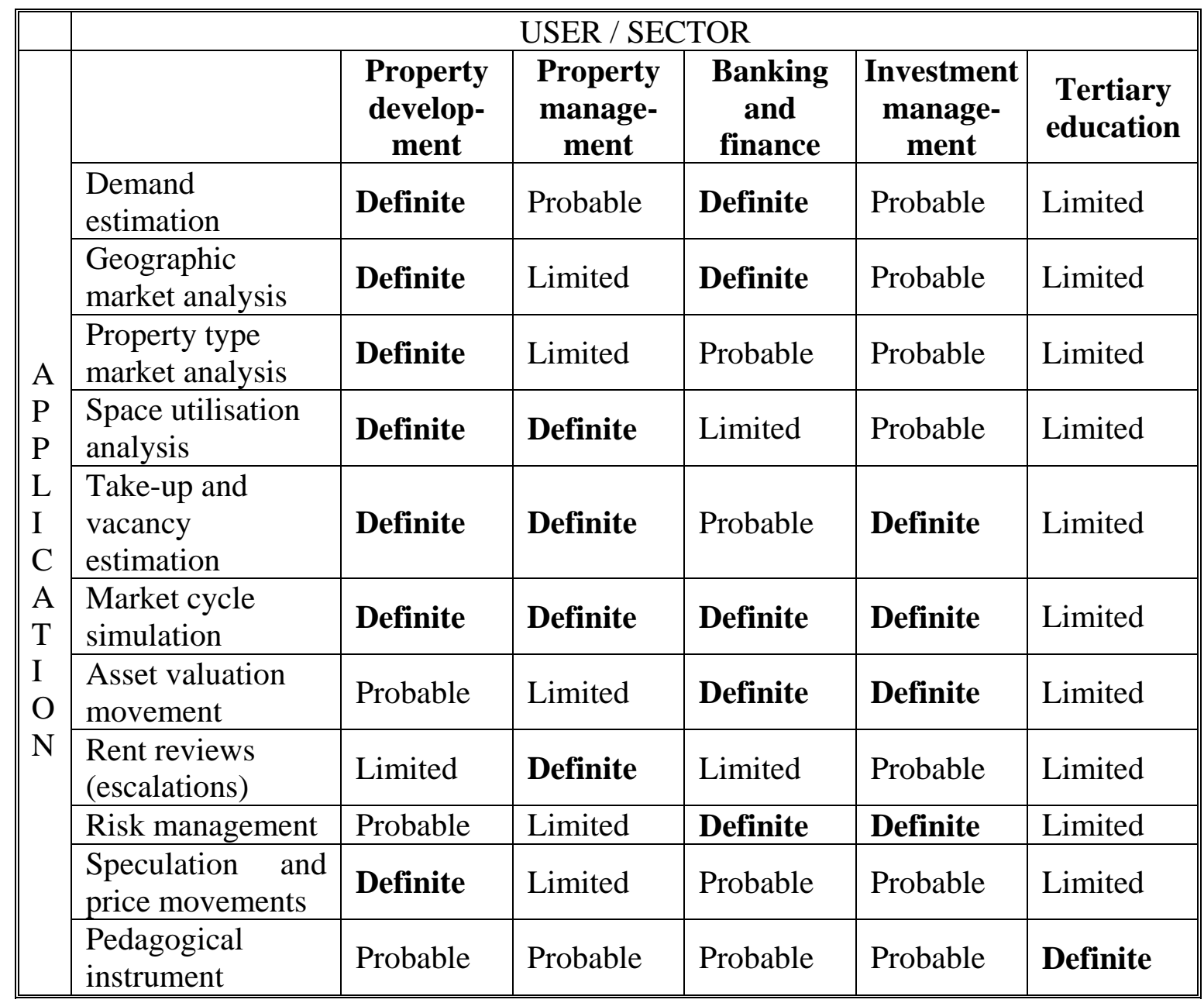

Notes: Definite: High degree of correlation between IPAMM capabilities and the core business of this sector.

Probable: IPAMM capabilities do not necessarily correlate with the core business of this sector but may, in certain instances, provide useful / insightful applications.

Limited: No definite correlation between IPAMM capabilities and the core business of this sector. 


\section{POSSIBLE IMPROVEMENTS AND OPPORTUNITIES FOR FURTHER RESEARCH}

An appraisal of IPAMM, with due cognisance taken of its fundamental assumptions, benefits and limitations, suggests that the model accurately captures important interrelationships between key property and asset market variables. As such, IPAMM is a useful multidimensional analytical and simulation instrument with diverse application possibilities. The following aspects can be identified as focus areas for future research:

1 Demand elasticity and hence, the slope of the demand curve in Quadrant 1. In this regard, calibration parameters ' $a$ ' and ' $b$ ' should be researched and refined.

2 The definition of minimum construction cost needs to be refined, specifically the significance and quantification of additional costs pertaining to site clearance, financing and land costs.

3 The depreciation factor utilised in Quadrant 4 requires empirical testing.

4 IPAMM is essentially a regression model based on a system of stochastic equations. A brief introduction to these econometric concepts, prior to further research and development on the model, may improve judicious manipulation of variables.

5 A comprehensive data pool should be created from which IPAMM can be calibrated and empirically tested in various geographic markets and for various property types.

6 On a more fundamental level, the use of artificial intelligence techniques such as neural networks and fuzzy expert systems seems to hold considerable promise for the development of improved real estate market models (see, e.g., Engelbrecht, 2002 and Negnevitsky, 2001).

It is concluded that IPAMM, within the parameters specified in its relatively simplistic system of equations, establishes a comprehensible framework that could evolve into a powerful decision support mechanism for property practitioners in various sectors of the economy.

\section{REFERENCES}

1 ACHOUR-FISCHER, D. (1999) "An integrated property market model: a pedagogical tool”, Journal of Real Estate Practice and Education, 2(1): 33-43.

2 AIREA (1987) The Appraisal of Real Estate, American Institute of Real Estate Appraisers, Ballinger Publishing Company: Cambridge. 
3 BALL, M., LIZIERE, C. \& MACGREGOR, B.D. (1998) The Economics of Commercial Property Markets, Routledge: New York.

4 CORCORAN, P.J. (1987) "Explaining the commercial real estate market”, Journal of Portfolio Management, 13: 15-21.

5 DIPASQUALE, D. \& WHEATON, W.C. (1992) "The markets for real estate assets and space: A conceptual Framework", Journal of American Real Estate and Urban Economics Association, 20(1): 181-97.

6 DIPASQUALE, D. \& WHEATON, W.C. (1996) Urban Economics and Real Estate Markets, Prentice-Hall Incorporated: New Jersey.

7 ENGELBRECHT, A.P. (2002) Computational Intelligence. An Introduction, Wiley: New York.

8 FISHER, J.D. (1992) "Integrating Research on Markets for Space and Capital”, Journal of American Real Estate and Urban Economics Association, 20(1): 161-80.

9 FISHER, J.D., DIPASQUALE, D. \& WHEATON, W.C. (1999) www.cbs.curtin.edu.au. Accessed June 2001.

10 FISHER, J.D., HUDSON-WILSON, S, \& WURTZEBACH, C.H. (1993) "Equilibrium in commercial real estate markets: linking space and capital markets”, Journal of Portfolio Management, 19: 101-7.

11 HAKFOORT, J. \& LIE, R. (1996) "Office space per worker: Evidence from four European markets”, The Journal of Real Estate Research, II(2): 183-96.

12 HENDERSHOTT, P.H. \& LING, D.C. (1984) "Prospective changes in tax law and the value of depreciable real estate", Journal of the American Real Estate and Urban Economics Association, 12: 297-317.

13 NEGNEVITSKY, M. (2001) Artificial Intelligence. A Guide to Intelligent Systems, Addison-Wesley: Harlow, England.

14 PYHRR, S.A., COOPER, J.R., WOFFORD, L.E., KAPPLIN, S.D. \& LAPIDES, P.D. (1989) Real Estate Investment. Strategy, Analysis, Decisions. ( $2^{\text {nd }}$ ed.) Wiley: New York.

15 RODE \& ASSOCIATES (1997) Rode's SA Property Trends, July.

16 RODE \& ASSOCIATES (1998) Rode's Report on the SA Property Market: 1.

17 RODE \& ASSOCIATES (2000) Rode's Report on the SA Property Market: 1.

18 ROULAC, S.E. (1996) "The strategic real estate framework: processes, linkages, decisions”, The Journal of Real Estate Research, 12(3): 323-46.

19 URBAN-ECON (1998) Pretoria Inner City Integrated Economic Development Policy, December, Urban-Econ Development Economists: Pretoria.

20 VIEZER, T.W. (1999) "Economic integration of real estate's space and capital markets”, Journal of Real Estate Research, 18(3): 503-19. 